\title{
Elaboración y evaluación de un antisuero para la detección inmunohistoquímica del virus de la rabia en tejido cerebral fijado en aldehídos
}

\author{
Nina Paola Lamprea, Lina María Ortega, Gerardo Santamaría, Ladys Sarmiento, \\ Orlando Torres-Fernández
}

\begin{abstract}
Laboratorio de Microscopía, Grupo de Morfología Celular, Instituto Nacional de Salud, Bogotá, D.C., Colombia
Introducción. El procedimiento estándar para el diagnóstico de la rabia requiere de muestras frescas del cerebro infectado, que se estudian mediante las técnicas de inmunofluorescencia directa y la inoculación en ratones. No obstante, a veces se necesita estudiar cerebros infectados con rabia mediante inmunohistoquímica de material fijado en aldehídos, pero los anticuerpos comerciales que se requieren son escasos y costosos.
\end{abstract}

Objetivos. Elaborar un antisuero antirrábico y probar su efectividad para reconocer antígenos de rabia en tejido cerebral preservado en aldehídos.

Materiales y métodos. Se inocularon conejos con una vacuna antirrábica producida en células Vero. Se obtuvo un antisuero que fue probado mediante inmunohistoquímica en cortes de cerebro de ratones infectados con rabia, obtenidos en diferentes condiciones experimentales y fijados en aldehídos. Además, se ensayó su utilidad en material de colección histopatológica de casos de rabia humana.

Resultados. Se demostró la especificidad del antisuero obtenido para la detección inmunohistoquímica de antígenos de la rabia en tejido nervioso fijado con aldehídos y procedente de material experimental y del archivo histopatológico. Además, el antisuero resultó ser útil para la detección del virus rábico en condiciones que se consideran desfavorables para la preservación de antígenos.

Conclusiones. La inoculación de vacuna antirrábica en conejos es un procedimiento fácil y seguro para la obtención de antisuero útil para la detección de antígenos de la rabia en muestras de tejido nervioso. Los cortes obtenidos con vibrátomo preservan mejor la antigenicidad en comparación con los tejidos incluidos en parafina, y permiten acortar el tiempo para hacer el diagnóstico inmunohistoquímico de la rabia.

Palabras clave: rabia, virus de la rabia, vacunas antirrábicas, anticuerpos, fijadores, fijación del tejido, inmunohistoquímica.

\section{Production and evaluation of an antiserum for immunohistochemical detection of rabies virus in aldehyde fixed brain tissues}

Introduction. The standard procedure for rabies diagnosis requires fresh samples of infected brain to be analyzed by two techniques, direct immunofluorescence and inoculation in mice. Rabies-infected, aldehyde-fixed brain tissues can be examined by immunohistochemistry, but the required commercial antibodies are scarce and expensive.

Objectives. An anti-rabies antiserum was produced and tested to evaluate the effectiveness of rabies antigen detection in aldehyde preserved brain tissue.

Materials and methods. Rabbits were inoculated with a rabies vaccine produced in Vero cells (originAfrican green monkey kidney). Anti-rabies antiserum was obtained and tested by immunohistochemistry in aldehyde-fixed brain sections of rabies-infected mice. Several experimental conditions were assayed. The usefulness of the antiserum in human pathology samples was also tested.

Results. The specificity of the antiserum was demonstrated for immunohistochemical detection of rabies antigen in fixed aldehydes nervous tissue both from experimental material and pathology archival collection. In addition, the antiserum was successful in detecting rabies virus under conditions that have been considered unfavorable for the preservation of antigens.

Conclusions. The inoculation of rabies vaccine in rabbits is an easy and safe procedure for obtaining antiserum useful for the detection of rabies antigen in samples of nervous tissue. Sections obtained on vibratome better preserve the viral antigenicity in comparison with paraffin-embedded tissues. This methods permit less expensive and more rapid immunohistochemical diagnosis of rabies.

Key words: rabies, rabies virus, rabies vaccines, antibodies, fixatives, tissue fixation, immunohistochemistry. 
La rabia es una enfermedad viral aguda con desenlace mortal, que afecta al sistema nervioso central y ha sido descrita en diversas especies de mamíferos. La rabia es un problema de salud pública, especialmente en países en desarrollo (1). En la década actual se han presentado en Colombia brotes de rabia en perros, humanos (2) y especies silvestres, particularmente en murciélagos; estos últimos han dado origen a muchos de los casos más recientes de rabia humana en el país (3).

El virus es transmitido por la mordedura o el contacto con la saliva de los animales infectados. Después de ser inoculado en la piel o en el músculo, el virus ingresa a través del sistema nervioso periférico e invade al sistema nervioso central. La diseminación ocurre exclusivamente a través de las neuronas, mediante el transporte retrógrado por los axones. Por esta razón, resulta paradójico que sea una enfermedad neurológica poco estudiada desde la perspectiva de la neurociencia $(4,5)$.

En nuestro laboratorio hemos estado desarrollando una línea de investigación enfocada a estudiar la vulnerabilidad neuronal a la infección con el virus rábico en un modelo de ratón, mediante el estudio de marcadores neuronales específicos y la estructura celular de los diferentes tipos de neuronas (6-10). La metodología de investigación requiere de material fijado en aldehídos que preserve tanto la morfología como la inmunorreactividad de los marcadores. Además, es necesario confirmar la existencia del virus en cada área estudiada del sistema nervioso, para establecer correlaciones entre su presencia en una estructura o tipo de neurona determinada y su efecto directo sobre la expresión de los marcadores neuronales o cualquier otro aspecto relacionado con la patogénesis de la rabia que pueda ser revelado por el estudio histológico.

El diagnóstico de la rabia se lleva a cabo, principalmente, por los métodos de inmunofluorescencia directa y la inoculación intracerebral en ratones lactantes. Puesto que estos métodos requieren de material cerebral fresco $(2,3,11)$, la oferta de anticuerpos para estudio inmunohistoquímico en tejido fijado es escasa y costosa. Por esta razón, fue necesario elaborar

\footnotetext{
Correspondencia:

Orlando Torres-Fernández, Laboratorio de Microscopía, Grupo de Morfología Celular, Instituto Nacional de Salud, Avenida Calle 26 NN$^{\circ}$ 51-20, Bogotá, D.C., Colombia otorresf@ins.gov.co

Recibido: 01/06/09; aceptado:20/08/09
}

un antisuero antirrabia y evaluar su efectividad en cerebros infectados y preservados en soluciones de aldehídos. Esto incluía la necesidad de probar su utilidad en diferentes condiciones experimentales y con los diferentes tipos de virus utilizados para la investigación en nuestro laboratorio, a saber, el virus obtenido a partir del tipo silvestre que circula en la naturaleza (virus calle) y el virus adaptado en laboratorio después de pases sucesivos (virus fijo) $(6,9,12)$.

Se evaluó, también, la utilidad del anticuerpo en muestras del archivo de la colección de casos de rabia humana conservadas en bloques incluidos en parafina. Se utilizaron conejos para obtener suero de una especie que pertenece a un orden taxonómico diferente a los roedores que son nuestro modelo de investigación.

\section{Materiales y métodos}

\section{Preparación e inoculación del antígeno}

Se trabajó con dos conejos machos de la raza Nueva Zelanda, de 12 semanas de edad y un peso aproximado de $3 \mathrm{~kg}$. Los animales se mantuvieron confinados en la sala de alta seguridad del bioterio del Instituto Nacional de Salud, bajo condiciones ambientales controladas, y suministro de alimento y agua ad líbitum. El protocolo de manejo de los animales utilizados en este estudio fue avalado por el Comité de Ética del Instituto Nacional de Salud.

A los conejos se les inyectó una solución de vacuna antirrábica Inmunovac $\circledast$, donada por Veterinaria de Colombia (Vecol, S.A.). Esta vacuna estaba compuesta por virus rábico (cepa L. Pasteur/2061 adaptada a células Vero) concentrado, inactivado, purificado, liofilizado y conservado en refrigeración a $4^{\circ} \mathrm{C}$. El diluyente, también suministrado por Vecol, estaba compuesto por una solución de cloruro de sodio $0,4 \%$ preparada en $0,5 \mathrm{ml}$ de agua destilada.

Para llevar a cabo la primera inoculación de los conejos, se mezclaron partes iguales de la dilución de la vacuna y adyuvante de Freund completo $(0,5 \mathrm{ml}$ de vacuna más $0,5 \mathrm{ml}$ de adyuvante). En las siguientes tres inoculaciones realizadas cada 15 días, el inóculo consistió en 0,5 ml de vacuna más $0,5 \mathrm{ml}$ de adyuvante incompleto. Para cada una de las inoculaciones las mezclas se hicieron haciendo pasar repetidamente la vacuna junto con el adyuvante, a través de una jeringa, durante un tiempo de 20 minutos. En cada una de las cuatro fechas de inoculación se inyectaron, en total, 0,5 $\mathrm{ml}$ de la mezcla dividida en cinco partes de $0,1 \mathrm{ml}$ 
cada una, por vía subcutánea, en áreas separadas entre sí, sobre el dorso del animal.

\section{Obtención y titulación del antisuero}

Quince días después de la última inoculación, los animales se anestesiaron y se les extrajo la totalidad de la sangre mediante punción cardiaca. La sangre se centrifugó durante 10 minutos a 3.000 rpm y el suero sobrenadante se sometió a una temperatura de $56^{\circ} \mathrm{C}$ para lograr la inactivación del complemento. A continuación, se hicieron alícuotas de antisuero inactivado que se transfirieron a una nevera a $-20^{\circ} \mathrm{C}$ para preservarlo hasta el momento de su uso en las pruebas inmunohistoquímicas. El mismo procedimiento se siguió para la obtención de una muestra de suero control tomada de sangre extraída de la vena marginal de la oreja de cada animal, antes de llevar a cabo la primera inoculación con el antígeno.

Para probar la eficacia del antisuero, se utilizaron muestras de cerebelo de un caso de rabia humana previamente diagnosticado por inmunofluorescencia directa e inoculación en ratón y cerebelo de uno de estos ratones inoculados para la confirmación de casos de rabia. Este material, junto con muestras no infectadas de cerebelo humano y de ratones, hacía parte de la colección de archivo correspondiente a trabajos realizados anteriormente por el grupo $(6,10,13)$ y era preservado en paraformaldehído al $4 \%$ en refrigeración a $4^{\circ} \mathrm{C}$. Estas muestras se procesaron mediante la técnica convencional para obtener bloques de tejido incluido en parafina y láminas con cortes de $7 \mu \mathrm{m}$ de espesor.

Se prepararon diluciones seriadas del antisuero de acuerdo con la siguiente secuencia: 1:50, 1:100, $1: 200,1: 400,1: 800,1: 1.600$ y 1:3.200. Utilizando una alícuota de cada una de ellas, se llevaron a cabo las reacciones inmunohistoquímicas en los cortes de cerebelo, de acuerdo con un protocolo previamente estandarizado (13) con otro antisuero, elaborado en hámster hace varios años en el antiguo Laboratorio de Inmunología del Instituto Nacional de Salud y que hasta ahora ha sido el único utilizado para los diagnósticos histopatológicos de rabia en tejido fijado en los laboratorios de patología y microscopía del Instituto Nacional de Salud $(2,3,6,10)$.

Brevemente, los cortes se desparafinizaron, se trataron inicialmente con tripsina al $0,05 \%$ durante 30 minutos y, luego, con peróxido de hidrógeno al $3 \%$ durante 30 minutos, seguido de lavados en tampón fosfato salino. A continuación, los cortes se incubaron en cámara húmeda con suero normal de caballo por 30 minutos, se retiró este suero y, sin lavar las preparaciones, éstas se incubaron con el antisuero obtenido; cada una de las siete diluciones antes relacionadas, se ensayó durante una hora.

Después de lavar las láminas con tampón de fosfato salino, se incubaron con un anticuerpo secundario anti-conejo (Sigma 1:300) durante una hora y, luego de lavarlas, se trataron con solución estándar del complejo avidina-biotina (Vector) durante una hora más. Para hacer visible la reacción, se utilizó la diaminobencidina como cromógeno y, finalmente, los cortes se colorearon con hematoxilina-eosina (13). Las muestras se observaron a los aumentos de 10X hasta 100X, buscando la máxima dilución que produjera una buena marcación del antígeno dentro de los cuerpos de Negri con la menor reacción de fondo.

El cuerpo de Negri es una inclusión intracitoplásmica formada por partículas virales y ribonucleoproteína viral, que se considera el rasgo patognomónico de la rabia $(4,12,14,15)$. Esta inclusión se tiñe de color marrón oscuro por el cromógeno empleado para hacer visible la reacción antígeno-anticuerpo de la técnica inmunohistoquímica.

\section{Ensayos de la inmunorreactividad al antisuero de rabia en otras muestras}

Una vez establecidos los títulos del antisuero, se siguió el mismo procedimiento descrito en la sección anterior para llevar a cabo diferentes ensayos sólo con la dilución elegida. En primer lugar, se probó el antisuero ensayando los siguientes controles: a) reacción inmunohistoquímica del antisuero en cortes de cerebelo no infectado; b) reacción inmunohistoquímica en tejido infectado pero reemplazando el antisuero por suero de conejo tomado antes de la inoculación.

Por otra parte, se hicieron pruebas del antisuero para evaluar la posibilidad de reacción cruzada con otras encefalitis virales. Para ello, se utilizaron muestras de cerebro de un ratón inoculado por vía intracerebral con virus del dengue y de dos ratones inoculados por la misma ruta con virus de la fiebre amarilla.

Para la prueba principal del antisuero, se seleccionaron cinco cerebros de ratones inoculados con virus de la rabia tipo calle y cinco cerebros de ratones inoculados con virus fijo de la misma colección de trabajos anteriores del grupo. Este material había sido fijado por perfusión intracardiaca con paraformaldehído al $4 \%$ y llevaba más de 
tres años de permanecer inmerso en la misma solución en refrigeración a $4^{\circ} \mathrm{C}$. Estos cerebros se procesaron para la obtención de cortes incluidos en parafina, como se describió en la sección anterior. Además, se ensayó el antisuero con material de archivo de 20 casos de rabia humana y uno de bovino, diagnosticados en el Instituto Nacional de Salud durante los últimos 20 años, mediante las pruebas de inmunofluorescencia directa e inoculación de ratón, y de los cuales se había procesado material fijado en formaldehído para estudio histopatológico.

También se ensayó el antisuero con la dilución elegida en muestras de cerebros de cinco ratones inoculados con virus calle, los cuales se sacrificaron en fase terminal de la enfermedad y se dejaron varias horas post mórtem a temperatura ambiente (10, 15, 20, 25 y 30 horas), luego de las cuales se extrajeron los cerebros y se fijaron por inmersión en paraformaldehído al 4\%. El objetivo de este experimento fue evaluar la efectividad del antisuero en muestras de tejido infectado que han sufrido muchas horas de degeneración post mórtem, tal como ocurre con frecuencia con las muestras enviadas para diagnóstico de rabia en cerebros de humanos y de animales silvestres.

Por último, se probó el antisuero en muestras de cerebro de ratones fijados con una mezcla de paraformaldehído al $4 \%$ y glutaraldehído al $0,5 \%$. De este material se obtuvieron cortes de $50 \mu \mathrm{m}$ utilizando un vibrátomo y sin necesidad de incluir el tejido en parafina ni en ningún otro medio de soporte. Las diferentes etapas de la reacción inmunohistoquímica en estos cortes se llevaron a cabo mediante suspensión de los mismos dentro de pequeños recipientes de vidrio y en agitación constante $(6,10)$

\section{Resultados}

El título seleccionado del anticuerpo fue de $1: 800$, esto es, la dilución a la cual se observaron cuerpos de Negri con mayor intensidad y con menor reacción inespecífica de fondo en el tejido nervioso (figura 1). En todas las muestras de cerebro de ratones inoculados con virus calle de la rabia, se observaron abundantes cuerpos de Negri, principalmente en el pericarión de neuronas piramidales de la corteza cerebral y en neuronas piriformes (células de Purkinje) del cerebelo (figura 1). Además, en los cortes de $50 \mu \mathrm{m}$ de espesor obtenidos con vibrátomo fue evidente la presencia del antígeno diseminado por todo el citoplasma

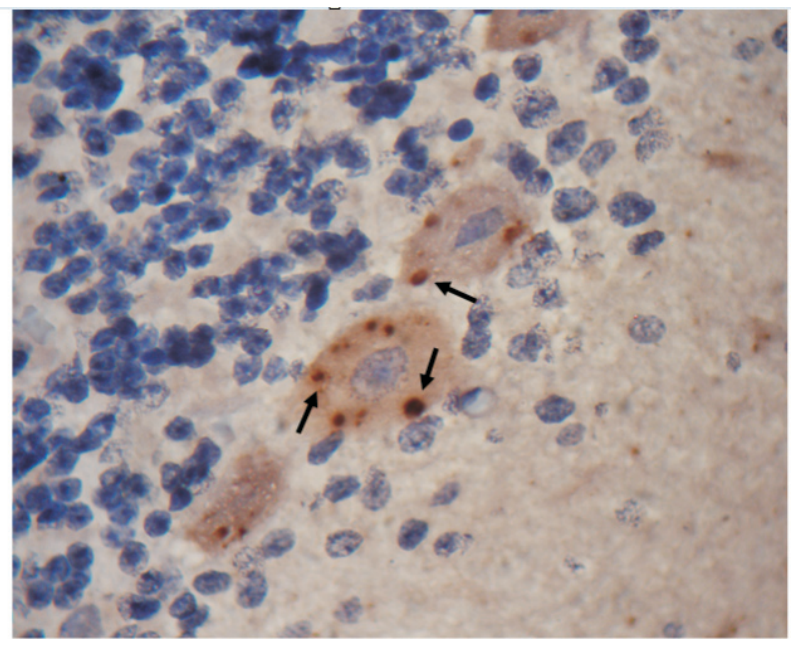

Figura 1. Imagen parcial de la corteza del cerebelo correspondiente a un caso de rabia humana. En el centro se observan los somas de dos células de Purkinje que exhiben varios cuerpos de Negri (flechas) inmunorreactivos a la rabia en el pericarion. Alrededor se notan abundantes núcleos de células de la capa granular. La fotografía fue tomada a un corte de tejido de $7 \mu \mathrm{m}$ de espesor que procede de material incluido en bloque de parafina. Técnica inmunohistoquímica revelada con diaminobencidina y contrastada con hematoxilina, 100X

y las dendritas de tal manera que se demarcó la morfología neuronal (figura 2). El título requerido para estos cortes más gruesos fue de 1:1.600.

En las muestras de ratones inoculados con virus fijo, la marcación positiva para la presencia del antígeno fue más intensa en el citoplasma y las dendritas, pero no se observaron cuerpos de Negri. No obstante, sí se notaron pequeñas inclusiones con marcación similar a la de los cuerpos de Negri dentro del citoplasma neuronal. En ningún caso se observó marcación positiva dentro del núcleo neuronal.

En el estudio retrospectivo de muestras del archivo del laboratorio de patología, se comprobó plenamente la presencia de cuerpos de Negri (figura 1) en los 20 especímenes humanos y en la muestra de cerebro de bovino.

Finalmente, no se observaron reacciones inespecíficas que pudieran interpretarse como 'falsos positivos' en ninguno de los controles empleados para rabia. Tampoco se detectó reacción cruzada en los tejidos cerebrales infectados con los virus del dengue y fiebre amarilla. La inmunorreactividad al virus de la rabia detectada por la presencia de cuerpos de Negri no se vio afectada, al menos cualitativamente, en ninguna de las muestras de ratones sometidas a varias horas de degeneración post mórtem antes de la fijación. La utilización de 


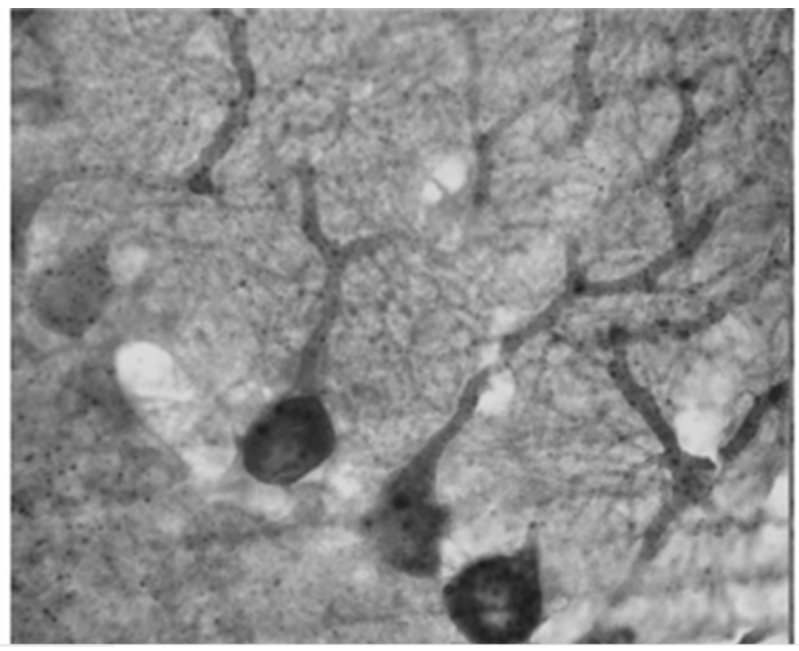

Figura 2. Imagen parcial de la corteza del cerebelo correspondiente a un ratón inoculado con virus de la rabia tipo calle. La inmunorreactividad intensa de los somas de las células de Purkinje y parte de su arborización dendrítica, revelan la alta concentración de antígenos de la rabia que enmascara a los cuerpos de Negri. La fotografía fue tomada a un corte de tejido de $50 \mu \mathrm{m}$ de espesor obtenido en vibrátomo. Técnica inmunohistoquímica revelada con diaminobencidina y sin coloración de contraste, 100X.

glutaraldehído en baja concentración como fijador adicional, permitió la inmunotinción de los cuerpos de Negri y de antígenos diseminados por todo el soma y la arborización dendrítica en cortes gruesos de tejido cerebral (figura 2).

\section{Discusión}

Hemos obtenido un antisuero antirrabia elaborado en conejos y hemos demostrado su especificidad para la detección de antígenos de rabia en neuronas infectadas de material fijado en formaldehído, paraformaldehído o glutaraldehído, y procesado por las técnicas histológicas convencionales, independientemente de la presencia de cuerpos de Negri. Una vez más, comprobamos la utilidad de emplear vacunas de rabia como antígeno. Este método, además de ser muy sencillo, lo hace más seguro para el experimentador $(16,17)$.

La inmunodetección de antígenos virales de la rabia, cuando se trata de diagnosticar la enfermedad a partir de tejido cerebral infectado, se hace preferencialmente utilizando material fresco que se analiza con la técnica de inmunofluorescencia directa y la confirmación mediante la inoculación en ratón de ese mismo material infectado $(2,3,11)$. No obstante, en algunas circunstancias es necesario llevar a cabo el diagnóstico con tejido cerebral sometido a fijación con aldehídos, especialmente cuando no se tienen indicios que hagan pensar en la rabia o si se tienen dificultades con el transporte de las muestras en fresco (11). Igualmente, es necesaria la fijación con aldehídos del tejido cerebral cuando se trata de llevar a cabo un trabajo experimental como el que realizamos en nuestro laboratorio.

El material fijado en aldehídos preserva muy bien la morfología del tejido y la estructura celular, así como las características antigénicas, especialmente de las proteínas. Además, a diferencia de lo que ocurre con la inmunofluorescencia, las preparaciones inmunohistoquímicas llevadas a cabo en tejido fijado son permanentes y permiten diferentes aplicaciones. Igualmente, facilitan la recolección de gran cantidad de especímenes para investigación y estudios de diagnóstico retrospectivo $(18,19)$.

Un comentario especial merece el hecho de haber podido llevar a cabo la inmunohistoquímica para rabia en cortes gruesos obtenidos en vibrátomo y en material fijado con glutaraldehído. Resultados similares se habían reportado con el antisuero elaborado en hámster y hasta ahora utilizado en el Instituto Nacional de Salud $(6,10,20)$. La posibilidad de llevar a cabo el diagnóstico de rabia en cortes que no requieren inclusión en parafina permite hacer un diagnóstico en menor tiempo y con una mejor preservación de los antígenos.

Por otra parte, el glutaraldehído se requiere para obtener una mejor calidad de la imagen del virus de la rabia y las células infectadas en microscopía electrónica $(12,14)$, pero afecta negativamente las reacciones inmunohistoquímicas, salvo contadas excepciones $(8,19,21)$. Por lo tanto, con los cortes obtenidos en vibrátomo de material infectado fijado en glutaraldehído se podrán llevar a cabo estudios de inmunomicroscopía electrónica de la infección y estudios de localización ultraestructural del virus con otros antígenos que toleran la fijación con glutaraldehído $(8,21)$.

En conclusión, el antisuero antirrábico obtenido en conejo no sólo será de utilidad para el trabajo de investigación experimental con animales de laboratorio, sino, también, para el diagnóstico de casos de rabia humana y de animales en condición silvestre. Además, al ser obtenido de una especie que no pertenece al orden de los roedores, se reduce la posibilidad de que se presenten reacciones cruzadas con el tejido cerebral de los ratones infectados con rabia que se utilizan como modelo para la investigación de esta enfermedad viral. 


\section{Agradecimientos}

Este trabajo fue posible gracias a la colaboración de Marcela Neira y Edgar Parra, del Grupo de Patología del Instituto Nacional de Salud, Jaime Castellanos, del Instituto de Virología de la Universidad El Bosque, y, especialmente, de José Manuel Granados de Vecol, quien suministró la vacuna antirrábica. Igualmente importante fue el aporte del grupo de profesionales del bioterio del Instituto Nacional de Salud.

\section{Conflicto de intereses}

Los autores consideran que no existe ningún conflicto de intereses que pueda afectar los resultados del trabajo.

\section{Financiación}

Subdirección de Investigación del Instituto Nacional de Salud. Nina Paola Lamprea, primera autora, se vinculó mediante la convocatoria 418 de 2007 del Programa Jóvenes Investigadores de Colciencias, convenio Colciencias-Instituto Nacional de Salud 93/2007.

\section{Referencias}

1. Wilde $\mathbf{H}$, Hemachudha $\mathbf{T}$, Jackson AC. Viewpoint: management of human rabies. Trans R Soc Trop Med Hyg. 2008;102:979-82.

2. Páez A, Rey G, Dulce A, Parra E, Díaz-Granados H. Brote de rabia humana transmitida por caninos en el distrito de Santa Marta, Colombia, 2006-2008. Biomédica. 2009;29:424-36.

3. Valderrama J, García I, Figueroa G, Rico E, Sanabria $\mathrm{J}$, Rocha N, et al. Brotes de rabia humana transmitida por vampiros en los municipios de Bajo y Alto Baudó, departamento del Chocó, Colombia 2004-2005. Biomédica. 2006;26:387-96.

4. Kristensson K, Dastur DK, Manghani DK, Tsiang H, Bentivoglio M. Rabies: interactions between neurons and viruses. A review of Negri inclusion bodies. Neuropathol Appl Neurobiol. 1996;22:179-87.

5. Fu ZF, Jackson AC. Neuronal dysfunction and death in rabies virus infection. J Neurovirol. 2005;11:101-6.

6. Torres-Fernández $\mathrm{O}$, Yepes GE, Gómez JE, Pimienta H. Efecto de la infección por el virus de la rabia sobre la expresión de parvoalbúmina, calbindina y calretinina en la corteza cerebral de ratones. Biomédica. 2004;24:63-78.

7. Torres-Fernández $\mathrm{O}$, Yepes GE, Gómez JE, Pimienta H. Calbindin distribution in cortical and subcortical brain structures of normal and rabies infected mice. Int J Neurosci. 2005; 115:1375-82.

8. Rengifo AC, Torres-Fernández O. Disminución del número de neuronas que expresan GABA en la corteza cerebral de ratones infectados por rabia. Biomédica. 2007;27:548-58.

9. Torres-Fernández O, Yepes GE, Gómez JE. Alteraciones de la morfología dendrítica neuronal en la corteza cerebral de ratones infectados con rabia: un estudio con la técnica de Golgi. Biomédica. 2007;27:605-13.

10. Lamprea $\mathbf{N}$, Torres-Fernández $\mathbf{O}$. Evaluación inmunohistoquímica de la expresión de calbindina en el cerebro de ratones en diferentes tiempos después de la inoculación con el virus de la rabia. Colom Med. 2008;39(Suppl.3):7-13.

11. Trimarchi CV. Diagnostic evaluation. In: Jackson AC, Wunner WH, editores. Rabies. San Diego: Academic Press; 2002. p. $307-49$

12. Iwasaki Y, Tobita M. Pathology. In: Jackson AC, Wunner WH, editores. Rabies. San Diego: Academic Press; 2002. p. 283-306.

13. Sarmiento L, Rodríguez G, De Serna C, Boshell J, Orozco L. Detection of rabies virus antigens in tissue: immunoenzymatic method. Patología. 1999;37:7-10.

14. Rodríguez G. Microscopía electrónica de la infección viral. Bogotá: Instituto Nacional de Salud; 1983. p. 119-39.

15. Rodríguez G, Sarmiento L. Rabia: el cuerpo de Negri. Biomédica. 1999;19:196-7.

16. Özkan Ö, Aylan O, Ates C, Celebi B. Production of antirabies immune sera. Etlik Veteriner Mikrobiyoloji Dergisi. 2004;15:49-54.

17. Redwan el-RM, Fahmy A, El Hanafy A, Abd El-Baky N, Sallam SM. Ovine anti-rabies antibody production and evaluation. Comp Immunol Microbiol Infect Dis. 2009;32:919.

18. Reblet C. Uso de las técnicas inmunocitoquímicas en neurobiología. En: Delgado JM, Ferrús A, Mora F, Rubia F, editores. Manual de neurociencia. Madrid: Editorial Síntesis; 1998. p. 387-8.

19. Hockfield S, Carlson S, Evans C, Levitt P, Pintar J, Silberstein L. Selected methods for antibody and nucleic acid probes. New York: Cold Spring Harbor Laboratory Press; 1993. p. 111-226.

20. Castellanos JE, Guayacán OL, Castañeda DR, Hurtado H. Uso de una técnica de inmunoperoxidasa para la detección de virus de rabia en cortes gruesos de cerebro. Biomédica. 1998;18:141-6.

21. Ribeiro-Da-Silva A, Priestley J, Cuello C. Pre-embedding ultrastructural immunocytochemistry. En: Cuello E, editor. Immunohistochemistry II. Chichester: John Wiley \& Sons; 1993. p. 181-227. 